\title{
REESCRITURAS DECIMONÓNICAS DEL SIGLO XV ESPAÑOL: EL SUSPIRO DEL MORO EN LA NARRATIVA DE MANUEL FERNÁNDEZ Y GONZÁLEZ
}

\author{
María Teresa del Préstamo Landín \\ Universidade de Vigo ${ }^{1}$
}

\begin{abstract}
RESUMEN
El topónimo Suspiro del Moro tiene su origen en la leyenda que narra la huida del rey Boabdil. La confrontación entre la derrota nazarí y la conquista de la España cristiana constituyó un motivo de extraordinaria pertinencia literaria en el siglo que da a luz los nacionalismos, la necesidad de crear un sentimiento de unión del pueblo frente a lo extranjero y una conciencia histórica. En el presente artículo abordaré este constructo histórico-nacional, así como su función dentro del historicismo naciente del XIX y las diferentes manifestaciones literarias que se llevaron a cabo, tomando como ejemplo las redactadas por Manuel Fernández y González.
\end{abstract}

Palabras Clave: Manuel Fernández y González, Suspiro del Moro, siglo XIX, novela histórica, reescritura

\section{Abstract}

The Suspiro del Moro place-name has its origin in King Boabdil's escape. The confrontation among the Nazari loss to the conquest of Christian Spain, was a motif of extraordinary literary relevance in the century that gave birth to nationalism and the need to create a sense of unity nation against the foreign and historical consciousness. In this article, I will present this historical-national construct, as well as its role in the nascent historicism of the nineteenth century and the different manifestations that were carried out taking as an example the ones written by Manuel Fernández y González.

KeY Words: Manuel Fernández y González, Suspiro del Moro, ninetenth-century, historic novel, rewrite

El Suspiro del Moro, puerto de montaña situado en Sierra Nevada, entre la Vega de Granada y el Valle de Lecrín, hereda su nombre de una breve leyenda ${ }^{2}$ surgida a raíz de los hechos de 1492 y que se refiere tanto a la huida a través de las montañas del último rey nazarí, Muhammad xII, más conocido como Boabdil, como a la humillación que sufre ante su propio pueblo frente a la cada vez más lejana Granada, recién conquistada por el bando cristiano. La tradición personifica en la figura de su madre, Aixa la Horra, la

\footnotetext{
Recibido: 19-05-2016 / Aceptado: 16-06-2016

1 Este trabajo se inserta en el ámbito del proyecto FFI2015-64107-P (MINECO/FEDER).

2 Documentos del s. XVI como la Historia del rebelión y castigo de los moriscos del Reyno de Granada de Mármol Carvajal y las epístolas familiares de Guevara, a las que haré referencia más adelante, junto con la novela Las Guerras de Granada de Pérez de Hita (1595), tratan de modo histórico el hecho situado en las cercanías de Padul y pasan a engrosar el corpus de fuentes a las que se referirán los escritores posteriores a la hora de remitir a la leyenda.
} 
deshonra que se le achaca al monarca: «llora como una mujer [...] ya que no supiste defender tu reino como hombre». ${ }^{3}$ La catastrófica sentencia materna será uno de los motivos que en mayor medida contribuirán a la difusión y fama de la leyenda, como metáfora no solo del final de un tiempo y una cultura peninsulares, sino de las desastrosas consecuencias que para un pueblo acarrea la debilidad de sus dirigentes.

La rendición y conquista de Granada en enero de 1492 es, posiblemente, uno de los hechos bélicos de mayor trascendencia literaria en las letras hispanas. El reino nazarí suponía el último reducto árabe en territorio peninsular y su derrota el final de una cruzada donde religión y política se entremezclaban. ${ }^{4}$

Tras la entrega de la ciudad, y a través de lo que se conoció como Tratado de Granada (1491), los Reyes Católicos concedieron a Boabdil una serie de pequeñas gratificaciones con el objetivo de suavizar la tensión entre la comunidad musulmana. ${ }^{5}$ Entre estas se encuentra el territorio de las Alpujarras en donde se refugiará y desde donde, tiempo después, emprenderá su camino a tierras africanas. Granada se conquista «al precio de la enajenación total de La Alpujarra y de buena parte de las tierras de la Vega». ${ }^{6}$

En el s. XVI encontramos algunas de las primeras referencias a la huida del rey. En la carta que Antonio de Guevara le dirige a Garci Sánchez de la Vega, este pone en boca de un morisco que forma parte de la comitiva de Boabdil:

Otro día después que se entregó la ciudad y el Alhambra al rey Fernando, luego se partió el rey Chiquito para tierra de Alpujarra, las cuales tierras quedaron en la capitulación que él las tuviese y por suyas las gozase. Iban con el rey Chiquito aquel día la reina su madre, delante, y toda la caballería de su corte, detrás, y como llegasen a este lugar do tú y yo tenemos ahora los pies, volvió el rey atrás

\footnotetext{
3 Fernández y GonZÁlez, M., El laurel de los siete siglos, Madrid, Gaspar y Roig, 1850, p. 196.

4 LADERO QUeSADA («Isabel y los musulmanes de Castilla y Granada», en Isabel la Católica y la Política: ponencias presentadas al I Simposio sobre el reinado de Isabel la Católica, celebrado en las ciudades de Valladolid y México en el otoño de 2000, Julio Valdeón Baruque (ed.), Valladolid, Ámbito D.L., 2001, p. 103), opina que, a pesar de ser tradicionalmente planteada como una batalla en nombre del cristianismo, tuvo en primer lugar un valor político, de reconquista. Por ello, en un comienzo, la rendición de la ciudad se produjo a cambio del respeto a sus habitantes y su fe. En palabras de GonZÁlez FerRin (Historia general de Al Ándalus: Europa entre Oriente y Occidente, Córdoba, Almuzara, 2006, p. 496), se aceptó el trato «a cambio de su mudejarismo, no su morisquización».

5 «Boabdil recibió en señorío hereditario las tahas de Berja, Dalia, Márjena, El Boloduy, Luchar, Andarax, Subiles, Ugíjar, Orgiva, El Jubeyel, Ferreira y Poqueira, salvando la opción preferente de la Corona en caso de que las quisiera vender o enajenar y la presencia de guarniciones castellanas en todas las fortificaciones costeras que los reyes fijasen [...]. Además de este señorío Boabdil se embolsó la enorme cantidad de 30000 castellanos de oro, vio reconocidas todas las propiedades que tenía antes de alcanzar el emirato y las de su madre, hermanas y mujer, todo ello exento y franco de contribuciones» en Ladero Quesada, M. Á., Castilla y la conquista del reino de Granada, Granada, Diputación provincial de Granada, 1987, pp. 96-97.
}

6 LAdero Quesada, M. Á., Castilla y la conquista del reino de Granada, ob. cit., p. 97. 
la cara para mirar la ciudad y Alhambra, como a cosa que no esperaba ya más de ver y mucho menos de recobrar. Acordándose, pues, el triste rey, y todos los que allí íbamos con él, de la desventura que nos había acontecido, y del famoso reino que habíamos perdido, tomámonos todos a llorar, y aun a nuestras barbas canas a mesar, pidiendo a la misericordia, y aun a la muerte, que nos quitase la vida. Como a la madre del rey, que iba delante, dijesen que el rey y los caballeros estaban todos parados: mirando y llorando el Alhambra y ciudad que habían perdido, dio un palo a la yegua en que iba, y dijo estas palabras: «Justa cosa es que el rey y los caballeros lloren como mujeres, pues no pelearon como caballeros»(p. 253). ${ }^{7}$

Lo más característico de esta primera versión del episodio es que la humillación se realiza de manera colectiva y no remite de manera exclusiva al rey. Además de todo ello:

Muchas veces oí decir al rey Chiquito, mi señor, que si como supo después, supiera allí luego lo que su madre de él y de los otros caballeros había dicho, o se mataran allí unos a otros, o se volvieran a Granada a pelear con los cristianos. ${ }^{8}$

No solo la humillación es colectiva y no personalizada, sino que ni siquiera se produce en su presencia. La sentencia materna, tan devastadora en otros relatos que sí muestran el enfrentamiento materno-filial, como el de Mármol Carvajal o los decimonónicos a los que voy a referirme, pierde por completo su fuerza increpadora al no dirigirse directamente al hijo. Este matiz argumental no reaparecerá en ninguna de las versiones posteriores.

En efecto, el cronista Mármol Carvajal publica en 1600, pocos años después que Guevara, su Historia de la rebelión y castigo de los moriscos del Reyno de Granada, que es reeditada en 1852 por Rivadeneyra. En ella atribuye el origen de esta leyenda a la tradición oral supuestamente originada a partir del testimonio de unos ancianos granadinos:

Mas unos moriscos muy viejos, que, según ellos decían, se hallaron presentes aquel día, nos certificaron que no había hecho más de hacer reverencia al Rey Católico y caminar la vuelta de la Alpujarra, porque cuando salió de la Alhambra había enviado su familia delante, y que en llegando a un viso que está cerca del lugar del Padul, que es de donde últimamente se descubre la ciudad, volvió a mirarla, $\mathrm{y}$, poniendo los ojos en aquellos ricos alcázares que dejaba perdidos, comenzó a suspirar reciamente, y dijo Alabaquibar, que es como si dijésemos Dominus Deus Sabaoth, poderoso Señor, Dios de las batallas; y que viéndole su madre suspirar y llorar, le dijo: «Bien haces, hijo, en llorar como mujer lo que no fuiste para defender

\footnotetext{
7 Cito en adelante por la edición que la RAE hizo en 1950-1952 de la obra de GUEVARA Libro primero de las epístolas familiares del illustre señor don Antonio de Gueuara, obispo de Mondoñedo, predicador y chronista del consejo del Emperador y Rey nuestro señor, Jorge Coci (imp.), Zaragoza, originalmente publicado en 1539-1541.
}

8 Guevara, A. de, ob. cit., p. 254. 
como hombre». Después llamaron los moros aquel viso el Fex de Alabaquibar en memoria de este suceso. ${ }^{9}$

Aunque no existe una versión canónica de la derrota del rey nazarí, es habitual en los novelistas románticos - como Fernández y González- partir de la historiografía del XVI como referencia de autoridad, hasta el punto de que títulos como el ya citado de Mármol Carvajal aparecen mencionados a pie de página como fuente de lo histórico.

Los textos históricos del XIX tampoco son ajenos a esta impronta de la leyenda revestida de pretendida fidelidad. Así, José Antonio Conde expone, en su Historia y dominación de los árabes en España (1820), una tesis sobre el origen del topónimo Suspiro del Moro sustentada en la imagen del rey llorando increpado por su madre: «Razón es que llores como mujer, pues no fuiste para defenderla como hombre». ${ }^{10}$ Para suavizar la dureza de estas palabras, Conde añade una intervención del visir en la que predice la fama que alcanzará el rey a pesar de la pérdida, aproximándose a la línea de Mármol Carvajal y alejándose de la de Guevara. A pesar de todo, el aspecto más destacable de la Historia de 1820 frente a las posteriores es el uso de los vocablos árabes tanto para la topografía como para los antropónimos. Frente al derivado Boabdil que usarán mayoritariamente los autores literarios, Conde mantiene los antropónimos de Abu Abdalah, Juzef Aben Tomixa ${ }^{11}$ y Feg Allah huakbar, que también encontraremos en Fernández y González.

El derrumbamiento final del último rey nazarí y la humillación materna resultan muy convenientes para la versión de la historia elaborada desde la perspectiva de los vencedores. El texto más condescendiente en este sentido acaso sea la versión redactada por Irving, que alude levemente al afán del rey nazarí por proteger la vida de su pueblo, de modo que su debilidad y su miedo se transforman en misericordia y sacrificio: «he hecho este asiento con los cristianos, deseando protegeros á vosotros [...] del hambre que nos aqueja». ${ }^{12}$ Esta imagen del rey como víctima de su destino

\footnotetext{
9 Mármol Carvajal, L. del, Historia del rebelión y castigo de los moriscos del Reyno de Granada, Madrid, M. Rivadeneyra, 1852, p. 151.

10 «El triste rey Abu Abdalah al llegar a Padul volvió los ojos a mirar por la postrera vez su ciudad de Granada, y no pudo contener sus lágrimas, y dijo: Alakuakbar... y dicen que la reina su madre le dijo: Razón es que llores como mujer, pues no fuiste para defenderla como hombre, y este sitio se llamó desde entonces Feg Alah huakbar, y su vizir Juzef Aben Tomixa que les acompañaba le dijo: Considera, señor, que las grandes y notables desventuras hacen también famosos á los hombres como las prosperidades y bienandanzas, procediendo en ellas con valor y fortaleza: y el cuitado rey llorando le dijo: ¿Pues cuáles igualan á las extraordinarias adversidades mías?» en CONDE, J. A., Historia y dominación de los árabes en España, París, Baudry, 1820, p. 667.

11 Son estas variantes de los nombres Aben Comixa y Feg Allah Akbar, a los que de este último modo me referiré en el artículo.

12 Me refiero a los Cuentos de la Alhambra, (IRVING, 1831, P. 229) publicados originalmente en 1833 por la Librería Hispano-Americana y traducidos al español por D.L.L.
} 
y dispuesto al sacrificio en aras de un bien superior es, no obstante, muy adecuada para el romanticismo; y los valores que representa cumplen el patrón exigido, casi sin proponérselo, por una parte significativa de la literatura historicista decimonónica.

En efecto, la cultura hispana de la primera mitad del siglo XIX está marcada por la necesidad de implantar un sentimiento de unión, un espíritu nacional común a todas las clases sociales. La alta tasa de analfabetismo y las deficiencias educativas frenaron la eficacia de la literatura en dicha tarea. Sin embargo, a través de diferentes mecanismos de difusión, la entrega pudo alcanzar estratos de la sociedad que se mantenían al margen del sistema educativo, contribuyendo a crear a través de un aparato mítico de héroes y gestas una identidad nacional. ${ }^{13}$ Es la educación sentimental la encargada de extender el volksgeist. Y si don Pelayo y el Cid fueron héroes que salvaron el reino cristiano cumpliendo una finalidad de unión y homenaje dentro del historicismo del XIX, la caída en desgracia de Boabdil y todos los que le rodean representa no solo la victoria cristiana y castellana, sino un ideal de fatalidad muy del gusto de los románticos que, además, resultará muy oportuna para este ideal en expansión.

En la leyenda, Boabdil aparece derrotado por una sociedad que avanza. No importan las causas que lo han llevado a ella, solo el final. Frente al fatalismo árabe, los narradores decimonónicos describen con frialdad el avance de las tropas castellanas reducidas a meros apuntes de personajes secundarios. Abandonado por la sociedad que llega y despreciado por la que lo vio nacer, el rey queda aislado del mundo, incapaz de defenderse. Los personajes de la leyenda aparecen en el XIX meramente esbozados, identificados tan solo a través de un rasgo. Se simplifican ignorando las situaciones y características que podrían modificarles o hacerles evolucionar: «Boabdil el desdichado, Muza el valiente, Aixa la altiva, Zoraida la renegada, Morayma la infeliz». ${ }^{14}$

El amor romántico está, así mismo, presente en las novelas y relatos de Fernández y González relacionados con Boabdil. Se personaliza en la ciudad, que se convierte en la máxima aspiración de enemigos y defensores y cuyo bien se prioriza por encima de todo. Ese deseo de proteger Granada es lo que impulsa a su rey a rendirla, descuidando las vidas de sus súbditos, y lo que guía a Muza a sacrificarse en un ademán suicida. Son estos dos hermanos quienes desean la victoria independientemente de su coste,

13 FeRnÁNDEZ PRIETO, C., «Literatura y nacionalismo español (1808-1900)», en José María Pozuelo Yvancos (dir.), Historia de la literatura española 8: Las ideas literarias 1214-2010, Madrid, Crítica, 2011, p. 445.

14 Fernández y GonzÁlez, M., La Alhambra: leyendas árabes, Madrid, Martínez, 1856, p. 887. Pedro CorreA («Estudio preliminar», en Ginés PÉREZ DE HiTA, Historia de los bandos de Zegríes y abencerrajes [primera parte de las Guerras Civiles de Granada], Granada, Universidad de Granada, 1999, pp. xxxv, cxxxv) atribuye a Pérez de Hita en Las Guerras civiles de Granada (1595) la recuperación del personaje de Muza del romancero, convirtiéndolo en un personaje falsamente histórico basado en un historiador inexistente: el Árabigo. 
quienes representan las dos caras de una misma moneda: uno renunciará incluso a su dignidad para protegerla, el otro invocará lo sobrenatural para lograrlo. Y ambos obtendrán el mismo final: la muerte, ya sea física en el caso de Muza o social en el caso de Boabdil.

A propósito de Granada, cabe destacar, asimismo, el hincapié que Fernández y González hace en el concepto de esclavización de la ciudad, en cuyo interior apenas se mantiene vida tras su caída bajo el poder de los cristianos. Esta idea, metafóricamente introducida en los textos a través del episodio de la entrega de las llaves, alcanza su mayor dramatismo en el instante en el que se declara la ciudad cristiana retirando de sus almenas la bandera nazarí. ${ }^{15}$

El escritor sevillano Manuel Fernández y González recurre hasta en tres ocasiones a la leyenda del Suspiro del Moro para construir sus novelas Allah Akbar: Leyenda de las tradiciones y sitio de Granada (1849), El laurel de los siete siglos (1850) y La Alhambra: leyendas árabes (1860). ${ }^{16}$ En estas novelas, realiza el autor las adaptaciones necesarias de acuerdo a las exigencias narrativas de cada título, pero el enfoque es casi siempre el mismo, con la voz narrativa situada del lado del vencedor, a pesar de que en su descripción subyace, en la mayoría de los casos, una firme compasión hacia el vencido.

En las tres novelas a las que acabo de referirme, el autor describe la caída del reino nazarí subordinándola a un contexto fantástico o histórico que la justifique. Siguiendo a Conde, respeta la nomenclatura árabe tanto para los topónimos como para los nombres. Incurre, no obstante, en un anacronismo reconocido en una nota a pie de página en El Museo Universal: en vez de hablar de la Reina de Castilla, Isabel la Católica, y del Rey de Aragón, Fernando el Católico, utiliza la nomenclatura de Reyes Católicos que se les otorgó tras la conquista de Granada. ${ }^{17}$

En todos estos títulos, Fernández y González muestra una Granada devastada, cautiva y derrotada, convertida en un mausoleo de su grandeza. La importancia de Boabdil varía de uno a otro, reducido en todas a la categoría de un pelele incapaz de

15 La imagen de la Granada esclava se introduce en las novelas de Fernández y González, en ocasiones a través de una sola frase "Granada era cautiva del cristiano» (FernándeZ y GonZÁlez, M., Allah-Akbar, Granada, M. Sanz, 1849, p. 174) y más detalladamente en Leyendas de la Alhambra (ob. cit., p. 886): «Por eso Granada calla, por eso Granada gime, por eso parece que el sol alumbra una ciudad y una comarca desiertas [...]. Granada, la sultana, la ciudad querida del Profeta, la alegría del Islam, es la cautiva vencida de la Cruz».

16 Las tres obras de Fernández y González seleccionadas así como Crónica de la conquista de Granada de Irving en 1831 (1829) fueron publicadas por entregas.

17 «En la época de la conquista de Granada no tenían aun este dictado don Fernando y doña Isabel: cabalmente por esta conquista les concedió este título el papa Alejandro vi: nosotros les llamamos Reyes Católicos porque con esta calificación se les reconoce por excelencia.» (FernÁndeZ Y GonZÁLez, M., 8 de enero de 1860, p. 11). 
luchar contra su destino, de convertirse en el héroe que su pueblo necesita. La soledad y la debilidad suya contrastan con la de su hermano, de quien llega a afirmar: «sin su horóscopo funesto él quizá hubiera hecho otras Asturias de las Alpujarras, y hubiera sido el Pelayo del pueblo moro». ${ }^{18}$

Allah-Akbar: leyendas de las tradiciones de sitio y conquista de Granada, publicada como libro en 1849, se inscribe en la línea arabista del autor. A pesar de haber sido escrita en su etapa de juventud, posiblemente sea una de sus obras de mayor éxito al constatarse la existencia de hasta ocho reimpresiones distintas. ${ }^{19}$ Se trata, sin embargo, de una adaptación de Las Guerras Civiles de Granada (1660) de Pérez de Hita. $^{20}$

Desde el inicio del texto, el tono es fúnebre. El aciago final nazarí está introducido por el personaje del genio y su comparación de los imperios árabe y egipcio.

La soberbia oprimió al desierto con el peso de las Pirámides [...]. Insolentes desafiaron al tiempo [...].

Los árabes quisieron dejar escrita su historia en las tierras de Occidente, y extendieron en Granada una de sus más hermosas páginas.

Creyeron que ella viviría con los siglos, y los siglos han carcomido sus pies [...].

No busquéis á Granada, Granada murió. ${ }^{21}$

El argumento, sin embargo, se centra en el desarrollo interno de la rebelión, cuando Muza alienta a su hermanastro a tomar medidas en contra de Boabdil, quien no se defenderá. El autor sevillano recrea las figuras históricas de los capitanes Juan Chacón (1452-1503), Hernán Pérez del Pulgar (1451-1531) y Fernández de Córdoba (1453-1515) como representantes de la España castellana. La historia, centrada en el bando nazarí, pasa durante los capítulos vi-X a la ciudad de Santa Fe, donde se produce el encuentro entre Zarayemal, sirvienta de Zoraida, y Juan Chacón. La primera, en nombre de su señora, le encomienda al caballero cristiano reparar su honor. Esta hazaña permitirá a Chacón la conquista de una mezquita de la que colgará un pendón cristiano que motivará la acción del siguiente capítulo. En el capítulo Ix, Zoraida actúa como puente entre los diferentes bandos, si bien la atención vuelve a centrase en el territorio

\footnotetext{
18 Fernández y GonZález, M., El laurel de los siete siglos, ob. cit., p. 11.

19 Si tomamos el criterio de las reimpresiones como indicador de popularidad, esta obra no dista demasiado de Martín Gil (Zamora, 1851), que con doce ediciones se convierte en la obra más popular del autor.

20 Cita Juan Ignacio Ferreras (La novela en España. Historia, estudios y ensayos. Tomo III: Siglo XIX. Primera parte [1800-1868], Madrid, La biblioteca del laberinto, S.L., 2010, p. 362) la edición de 1660 de Carlos de Sercy, mientras que Correa utiliza la de Blanchard-Demouge (1913: Bailly-Baillière), reproducción de la edición príncipe (1595).

21 Fernández y GonzÁlez, M., Allah-Akbar, ob. cit., pp. 4-.5.
} 
nazarí donde se muestra el rechazo de su pueblo ${ }^{22}$ y donde Gonzalo de Córdoba debe localizar a la mora Haxima. En los capítulos x y xI, «La toma de Granada» y «El suspiro del moro», el narrador vuelca su atención, nuevamente, en Boabdil.

Fernández y González ${ }^{23}$ expone el antecedente de la debilidad de Boabdil: la traición y la rendición interna. Nada puede salvar a la ciudad, ni un buen rey que muera en el campo de batalla, ni Muza, en quien se personifica la esperanza de la victoria, que desaparece. ${ }^{24}$

Durante la obra, el narrador recurre en numerosas ocasiones a descripciones de carácter oriental para la corte, con un estilo recargado en el que no deja de recurrir a los epítetos e impide que el lector profundice en los personajes. ${ }^{25}$ La narración de la acción es, sin embargo, aséptica, apenas si transmite emoción alguna, hasta el capítulo XI, centrado en la figura de Boabdil y su huida a través del monte Padul, donde se situaría el legendario puerto y que, tras la escena, toma el nombre de Feg-Allah-Akbar, Suspiro del Moro.

En El laurel de los siete siglos (1850), el narrador da comienzo al texto con una oposición entre el siglo XIX y el XV. Enmarcada en el mismo cuadro histórico que su predecesora, lo sobrenatural adquiere un peso fundamental. Si bien en Allah-Akbar este se reduce a la figura del genio que actúa como narrador, en El laurel supone un elemento activo durante toda la historia, ya que de él se hace derivar la posible solución y final de la guerra. ${ }^{26}$

$\mathrm{Su}$ especial interés radica en su protagonista: Muza. Al contrario que en el resto de las obras de Fernández y González a las que vengo refiriéndome, en El laurel el rey no es más que un personaje secundario al servicio del héroe, que recurre a lo sobrenatural para lograr la victoria.

A pesar de que se sigue respetando la terminología árabe, la sintaxis se simplifica en este texto con respecto a la obra anterior. Así, mientras en la novela de 1849 leemos: «Sí, llora como una mujer, menguado, ya que como hombre defender no supiste tu corona», ${ }^{27}$ en la del año 1850:

-Sí, llora como una mujer, le dijo con desprecio la sultana Aixa, llora, ya que no supiste defender tu reino como hombre..$^{28}$

\footnotetext{
22 Fernández y GonZÁlez, M., Allah-Akbar, ob. cit., p. 155.

23 Fernández y GonZÁlez, M., Allah-Akbar, ob. cit., pp. 83-90 y 95.

24 Fernández y GONZÁlez, M., Allah-Akbar, ob. cit., p. 173.

25 Carrasco Urgoiti, M. S., El moro de Granada en la literatura: del siglo XV al XIX, Tesis (Versión digital), Alicante, Biblioteca Virtual Miguel de Cervantes, 2010.

26 Fernández y GonZÁlez, M., El laurel de los siete siglos, ob. cit., pp. 22 y 199.

27 Fernández y GonzÁlez, M., Allah-Akbar, ob. cit., p. 149.

28 Fernández y GonzÁlez, M., El laurel de los siete siglos, ob. cit., p. 196.
} 
En el capítulo centrado en Boabdil, la voz narrativa dirige la atención del lector hacia Muza. Frente a la humillación del rey, reducida a un mero apunte, el narrador se explaya en la descripción del héroe:

El emir, con la boca seca y entreabierta, los ojos áridos y rojos, el pecho agitado por una respiración violenta, pálido, desencajado, con la pica fuertemente apretada entre sus manos, permaneció inmóvil, silencioso, sin apartar la vista del ejército que avanzaba en paso de arremetida [...] entonces un grito terrible, amenazador, insensato brotó de su garganta, sus ojos rodaron ferozmente en sus órbitas, en el aire su terrible pica y apretando los acicates á su corcel, gritó:

-¡Samyel! ¡Samyel! ¡Tú que eres veloz como el rayo, vuela! ¡Vuela hacia ellos! ¡Ha llegado la hora de morir con la patria!. ${ }^{29}$

Ni una palabra se dirige en el final a los castellanos o a Boabdil, la figura legendaria queda reducida a un apunte que apenas si dibuja un personaje desesperado al que ni la muerte le es concedida. Caída Granada, lo sobrenatural vuelve a hacer acto de presencia exigiendo el pago a sus servicios. ${ }^{30}$

El último volumen en el que Fernández y González trata esta historia es en el conjunto de relatos incluidos en La Alhambra: leyendas árabes (1856). En la antepenúltima de las mismas, «El patio de los leones», se incluyen las referidas a la toma de la ciudad. El autor recicla para ella parte de la historia que había tratado en Allah Akbar. Los capítulos V, VI, x y XI de esta ${ }^{31}$ se reescriben ahora, ${ }^{32}$ en ocasiones, sin ser modificados. Así pasa con la historia de los Siete Durmientes en la obra de 1849:

Moraba en una ciudad, fuerte y poderosa, un rey, a quien todos llamaban, débil y cobarde; todos se mofaban de él... a la espalda, porque es fama que el tal rey llevaba sus venganzas hasta la crueldad..$^{33}$

que se repite:

Moraba en una ciudad fuerte y poderosa un rey á quien todos llamaban débil y cobarde.

Todos se mofaban de él... a su espalda, porque es fama que aquel rey llevaba sus venganzas hasta la crueldad. ${ }^{34}$

El capítulo de «La toma de Granada» de 1849 se reescribe y divide en dos: «La agonía de Granada» y «La toma de Granada». Si bien el comienzo es el mismo en

\footnotetext{
29 FERnÁNDEZ y GonZÁLEZ, M., El laurel de los siete siglos, ob. cit., p. 197.

30 Fernández y GonzÁlez, M., El laurel de los siete siglos, ob. cit., p. 199.

31 FernándeZ y GonZÁlez, M., Allah-Akbar, ob. cit., pp. 83-123, 168-180.

32 Fernández y GonZÁlez, M., La Alhambra: leyendas árabes, ob. cit., pp. 827-858, 869-898.

33 Fernández y GonZÁlez, M., Allah-Akbar, ob. cit., pp. 87-88.

34 Fernández y GonZÁlez, M., La Alhambra: leyendas árabes, ob. cit., p. 830.
} 
ambos volúmenes, ${ }^{35}$ en el de 1856 el narrador se detiene en describir el clima interno de la ciudad con más profusión, centrándose en la hambruna que la asuela y en el proceso que da lugar a la capitulación. ${ }^{36}$

El capítulo «La toma de Granada» de Leyendas de la Alhambra se inicia con el acercamiento del ejercito vencedor a una ciudad desierta. A la opulencia del bando cristiano se opone el «melancólicamente conmovido hermoso semblante de la reina». ${ }^{37}$ El narrador se explaya describiendo la ciudad y cómo los dirigentes abandonan a los habitantes a su suerte. Se le exige al rey responsabilidad política y militar, acusándolo de la derrota. Como novedad con respecto al mismo capítulo de Allah-Akbar, Fernández y González incluye la intervención de Aben Comixa calcada del texto de Conde, como una funesta enseñanza del final para la historia. ${ }^{38}$

Con motivo de la Guerra de África (1859-1860), Fernández y González recupera para El Museo Universal los dos últimos capítulos de Allah-Akbar publicándolos en su folletín. Les añade un memorándum de Isabel la Católica como prefacio, comenzándolo en el momento de su muerte, y finaliza con la voz de Cisneros como justificación de la guerra en Granada y en África. ${ }^{39}$

No son excesivamente numerosos los ejemplos de autores tanto nacionales como extranjeros que se han ocupado de esta leyenda. Carrasco Urgoiti ${ }^{40}$ atribuye a Irving y a Chateaubriand la supervivencia decimonónica del interés por la tradición mora, que se completará con una composición menor de Alarcón posterior a las obras de Fernández y González.

Así, Carrasco Urgoiti ${ }^{41}$ cita The Conquest of Granada (1670) de Dryden como testimonio literario de la leyenda previo al romanticismo, aunque matiza que los

\footnotetext{
35 En el libro La Alhambra (1856) se mantiene intacto el inicio del capítulo con respecto al de 1849, con una variación menor. De este modo, la cita «Gonzalo Fernández de Córdoba había sido encargado por los reyes de formalizar el sitio de la ciudad» sufre un pequeño cambio al especificar por separado a cada uno de los monarcas y no como una misma figura. (FernÁNDEZ y GonZÁLEZ, M., Allah-Akbar, ob. cit., p. 168 y FERNÁNDEZ y GONZÁLEZ, M., La Alhambra: leyendas árabes, ob. cit., p. 877).

36 Fernández y GonZÁlez, M., La Alhambra: leyendas árabes, ob. cit., pp. 878-880.

37 Fernández y GonZÁlez, M., La Alhambra: leyendas árabes, ob. cit., p. 880.

38 La sentencia «Considera, señor, que las grandes y notables desventuras hacen también famosos á los hombres como las prosperidades y bienandanzas, procediendo en ellas con valor y fortaleza.» (FerNÁNDEZ y GonZÁlez, M., La Alhambra: leyendas árabes, ob. cit., p.898) está tomada del volumen de Conde (Historia y dominación de los árabes en España, ob. cit., p. 667), al que me refería en la décima nota de este artículo.

39 «He aquí mi noble señora, que yo cumpliendo tu voluntad, traigo mi cruz de Toledo sobre África, por Dios, por ti y por España.» (FERNÁNDEZ Y GonZÁLeZ, M., «La toma de Granada y el suspiro del moro», ob. cit., p. 2).

40 Carrasco Urgotti, M. S., ob. cit.,

41 Carrasco Urgoiti, M. S., ob. cit.,
} 
ejemplos en las literaturas en lengua inglesa son más bien escasos. Chateaubriand partiría asimismo de la leyenda en Le dernier Abencerraje (1826), trabajándola como punto de inicio. A diferencia de los demás autores a los que me he referido, más centrados en las guerras o en la caída de la ciudad, la Granada nazarí del francés es simplemente aquí un recuerdo, una sombra que persigue a los protagonistas. ${ }^{42}$

Washington Irving, por su parte, dedica dos narraciones al episodio. La primera de ellas se inscribe en la obra The Conquest of Granada - A Chronicle of the Conquest of Granada from the Ms. of Fray Antonio Agapida (1829) y la segunda se corresponde con The Alhambra (1832). ${ }^{43}$

En el primer caso la historia se sitúa en el penúltimo capítulo: «Conmociones en Granada: entrega de la ciudad», ${ }^{44}$ que se inicia con la rendición y el acuerdo ya firmado, eliminándose en la traducción fragmentos referentes al aspecto del monarca que podrían contribuir a la imagen de este: «He was reduced to a skeleton; his eyes glowed like coals in their sockets, and his speech was little better tan frantic raving». ${ }^{45}$

Boabdil afronta la culpa ante su pueblo y se responsabiliza de la caída de Granada como consecuencia del enfrentamiento con su padre, tal y como mostrará posteriormente Alarcón en El suspiro del moro. ${ }^{46}$ Este discurso, al igual que ocurre en otras composiciones, suaviza la humillación de Boabdil al justificar su acción:

Bien sé que mis culpas, y el haberme alzado con el reino contra mi padre, son la causa de los males que padecemos, y que tan amargamente lloro. Por vuestro respeto, no por el mío, he hecho este asiento con los cristianos, deseando protegeros á vosotros, y á vuestras mujeres e hijos contra los horrores del hambre que nos aqueja, y por aseguraros el ejercicio de vuestra religión, y la posesión de vuestros

\footnotetext{
42 «Lorsque Boabdil, dernier roi de Grenade, fut obligé d'abandonner le royaume de ses péres, il s'arrêta au sommet du mont Padul. De ce lieu élevé on découvrait la mer oú l'infortuné monarque allait s'embarquer pour l'Afrique; on apercevait aussi Grenade, la Vega et le Xénil, au bord duquel s'élevaient les tentes de Ferdinand et d'Isabelle. A la vue de ce beau pays et des cyprés qui marquaient encore çà et là les tombeaux des musulmans, Boabdil se prit à verser des larmes. La sultane Aïxa, sa mère, qui l'accompagnait dans son exil avec les grands qui composaient jadis sa cour, lui dit: «Pleure maintenant comme une femme un royaume que tu n'as pas su défendre comme un homme.» Ils descendirent de la montagne, et Grenade disparut à leurs yeux pour toujours.» (CHATEAUBRIAND, F. R., VicomTE DE, «Le Dernier Abencerage» en Atala. René. Le Dernier Abencerage, Paris, Pourrat Frères, 1834, p. 145).
}

43 «El material histórico está organizado en forma clara y es abundantísimo, pues el autor narra los principales episodios de la campaña, vistos desde el campo cristiano, así como los acontecimientos más importantes que agitaron durante esos años la corte mora» (CARRASCO URGOITI, M. S., ob. cit., Tesis (Versión digital), Alicante, Biblioteca Virtual Miguel de Cervantes, 2010).

44 La traducción de 1831 llevada a cabo por Jorge W. Montgomery es parcial, ya que se alteran los capítulos al fundirse entre sí. Los capítulos XCVIII y XCIX («Commotions in Granada» y «Surrender of Granada», respectivamente) se agrupan en uno solo. En adelante, cito en español por la traducción de 1831 y en inglés por la edición de Carey, Lea \& Carey, 1829.

45 Irving, W., Chronicle of conquest of Granada, Philadelphia, Carey, Lea \& Carey, 1829, p. 287.

46 Alarcón, P. A. de, El suspiro del moro, Granada, Ventura y Sabatel, 1867. 
bienes, libertad y leyes, bajo el dominio de otro Soberano más venturoso que vuestro desgraciado Boabdil..$^{47}$

Tras la entrega de llaves, Irving narra el encuentro entre Boabdil y su familia camino de las Alpujarras. En lo alto del último monte desde el que se ve la ciudad, la comitiva se gira y observa Granada. Aprovecha Irving la ocasión para describir la última visión de la Alhambra que leeremos en la obra:

A los rayos de un sol resplandeciente, relumbraban los dorados chapiteles de sus alcázares y mezquitas; las erguidas almenas y torres de la Alhambra presentaban una majestuosa perspectiva; y en derredor, desplegaba la vega su verde seno, por donde corría engastada la líquida plata del cristalino Genil. ${ }^{48}$

Sin embargo, no es el horizonte granadino lo que desata la emoción en Boabdil. Mientras contemplan la ciudad, las tropas conquistadoras anuncian la toma de la misma mediante la salva y es esa explosión lo que provoca la crisis nerviosa del antiguo rey. Y a ella le sigue el reproche de su madre: «Bien haces de llorar como mujer, lo que no fuiste para defender como hombre». ${ }^{49}$

El reproche, en el que no insiste el autor estadounidense, precede a la intervención de Aben Comixa, ${ }^{50}$ que mantiene el tono consolador que se refleja también en el resto de autores y que procede, asímismo, a nombrar el monte:

De aquí vino el llamarse Fez Alá Ackbar un cerro que está cerca del Padul, pero el punto desde el cual miró el Rey á Granada por la vez postrera, se denomina aun hoy dia, el último suspiro del moro. ${ }^{51}$

${ }_{47}$ En IRving, W., Crónica de la conquista de Granada, Jorge W. Montgomery (trad.), Madrid, I. Sancha, 1831 , p. 229. «It was my crime in ascending the throne in rebellion against my father -said he mournfully- which has brought these woes upon the kingdom; but Allah has grievously visited my sins upon my head. For your sake, my people, I have now made this treaty, to protect you from the sword, your little ones from famine, your wives and daughters from outrages of war; and to secure you in the enjoyment of your properties, your liberties, your laws, and your religion, under a sovereign of happier destinies tan the ill-starred Boabdil» (Irving, W., Chronicle of conquest of Granada, ob. cit., p. 288).

48 En Irving, W., Crónica de la conquista de Granada, ob. cit., p. 234. «The sunshine, so bright in that transparent climate, lit up each tower and minaret, and rested gloriously upon the crowning battlements of the Alhambra; while the vega spread its enameled bosom of verdure below, glistening with the silver windings of the Xenel» (Irving, W., Chronicle of conquest of Granada, ob. cit., p. 295).

49 En Irving, W., Crónica de la conquista de Granada, ob. cit., pp. 234-235. «You do well -said she- to weep like a woman, for what you failed to defend like a man!» (IRVING, W., Chronicle of conquest of Granada, ob. cit., p. 295).

50 «The vizier Aben Comixa endeavored to console his royal master. -Consider, sire -said he- that the most signal misfortunes often render men as renowned as the most prosperous achievements, provided they sustain them with magnanimity» (IRvING, W., Chronicle of conquest of Granada, ob. cit., p. 295).

51 En Irving, W., Crónica de la conquista de Granada, ob. cit., p. 235. «From this circumstance, the hill, which is not far from the Padul, took the name of Feg Allah Acbar: but the point of view commanding the last prospect of Granada, is known among Spaniards by the name of El último suspiro del Moro, or, 
A diferencia de lo que sucede en los textos de Fernández y González, quien pierde interés en la figura de Boabdil una vez ha abandonado Granada, en el primero de los tres apéndices, «Suerte del Rey chico Boabdil», se incluye la historia de este desde su retiro hasta su muerte. ${ }^{52}$

El segundo acercamiento de Irving al motivo lo realiza, dos años más tarde, en una breve anotación en The Alhambra (1832), traducida como Cuentos de la Alhambra (1833)..$^{53}$ La descripción que realiza de la escena es totalmente aséptica y superficial, y carece de la empatía hacia el vencedor o el vencido que intentan transmitir el resto de autores a los que me he referido. ${ }^{54}$

En España, Alarcón dedica varias composiciones de diferentes géneros al suceso. El primero de ellos, un canto presentado al certamen del liceo de Granada de 1867, es posterior a todas las creaciones de Fernández y González. La segunda de ellas es una breve descripción en La alpujarra, poco distinta de la de Irving. El suspiro del moro alaba en tono elegíaco al vencedor, de modo mucho más enaltecedor que en la descripción aséptica de Irving o en las empáticas narraciones del autor sevillano. Granada, en palabras de Alarcón, se identifica con el paraíso perdido, paraíso caído por el orgullo y la traición a Muley Hacen. Es este amotinamiento, anterior a toda la historia, lo que provoca el fatal desenlace. ${ }^{55} \mathrm{Y}$ al igual que Fernández y González situaba en boca del visir la pervivencia del recuerdo de la desdicha traída por Boabdil, Alarcón equipara la caída de la monarquía con la de la ciudadela y expresa el eterno recuerdo que esta suscitará en el mundo. ${ }^{56}$

La principal diferencia existente entre la composición de Pedro Antonio de Alarcón y sus predecesores se establece en la figura materna. A pesar de que la tradición insiste en mostrarnos una madre despectiva (y Fernández y González no se

\footnotetext{
"The last sigh of the Moor"» (IRvING, W., Chronicle of conquest of Granada, ob. cit., p. 296).

52 Irving, W., Crónica de la conquista de Granada, ob. cit., pp. 241-245. En la edición inglesa de 1829, pp. 423-429.

53 La obra es traducida por D.L.L. y publicada en París por Librería Hispano-Argentina, 1833.

54 «Mira ahora hacia el sur, al pie de dichas montañas, una línea de áridas colinas por las que camina pausadamente una larga recua de mulas. Allí se representó la escena última de la dominación musulmana. Desde la cima de una de esas colinas, el infortunado Boabdil lanzó su postrera mirada sobre Granada y dio rienda suelta a la angustia de su corazón. Es el suspiro del moro, lugar famoso en cuentos y leyendas.» (Irving, W., Cuentos de la Alhambra, D.L.L. (trad.), París, Librería HispanoAmericana, 1833, p. 119).

55 «iAsí cumplióse lo que escrito estaba... / pero escrito por Dios, que al hombre dijo: / «Honrarás a tu padre.» - Así acaba / el príncipe rebelde, ingrato hijo / a quien su padre ciego, que espiraba,/ una vez y otra feroz maldijo...» (ALARCón, P. A. de, El suspiro del moro, ob. cit., p. 11).

56 «iSuspiro amargo, lúgubre, espantoso, / que aun en Granada tétrico resuena, / turbando de los siglos el reposo / y de la muerte la quietud serena! / [...] ¡Y sonará implacable, tremebundo, / mientras se acuerde de la Alhambra el mundo!» (AlarCón, P. A. de, El suspiro del moro, ob. cit., p. 14).
} 
aleja de este patrón), Alarcón introduce la duda del amor dolido duplicando el fondo del personaje:

Y con brusco desdén mal comprimido, (¡tal vez con hondo amor desesperado!) apartóse del príncipe afligido, y, mirando colérica á Granada, huyó vencida, pero no domada. ${ }^{57}$

Emilio Castelar escribe en 1885 El suspiro del moro: Leyendas tradiciones, historias referentes a la conquista de Granada y a finales del s. XIX también publica un volumen sobre las historias y leyendas granadinas. En ambas se detiene en el motivo, describiéndolo con cuidado hasta casi esbozar una pintura. ${ }^{58}$

Las descripciones del paisaje que construye son muy minuciosas. Recrean un paisaje al atardecer mediante imágenes estáticas que muestran al lector una postal. ${ }^{59} \mathrm{El}$ final de la historia apenas ocupa unas líneas. Solo se menciona entre los personajes a Boabdil y Aixa, siendo la figura materna la única que tiene voz en el texto.

Como podemos constatar, pese a que los mimbres argumentales apenas difieren en las diferentes versiones literarias de la leyenda, Fernández y González las elabora en base a sus propias ideas y presupuestos románticos. El reciclaje de un texto tan marcadamente volcado en el perdedor sobrevive inmune a la justificación y actualización histórica que el autor sevillano realiza en 1860. Independientemente del intento de loa a la Reina Isabel la Católica o de las palabras atribuidas a Cisneros, son las muertes inevitables de Boabdil y Muza las que consiguen emocionar al lector.

Chateaubriand, Irving, Alarcón y Castelar recrean el motivo de una manera fría, centrados más en la anotación que en el desarrollo de la leyenda, en ocasiones abordada de forma anecdótica, casi superficial, narrada siempre desde la perspectiva del vencedor. El lamento de Boabdil en el Suspiro del Moro, narrado y descrito por

\footnotetext{
57 Alarcón, P. A. de, El suspiro del moro, ob. cit., p. 15.

58 «Por fin, al caer la tarde solemne de aquel día terrible, llegó la corte granadina, como en tropel y confusión, al célebre boquete conocido con el nombre de Padul y que separa los valles alpujarreños del valle regado por Darro y por Genil.» (CASTELAR, E., El suspiro del moro: Leyendas, tradiciones, historias de la conquista de Granada, 1885, p. 453).

59 «El cielo espléndido, el sol fulgurante, las montañas encendidas como volcanes, la vega inmensa dilatándose hasta donde la vista se dilata, las colinas pobladas por torreones parecidos á corales gigantescos, la ciudad atravesada por el Darro y lamida por el Genil, entreabierta y hermosísima como la fruta de su nombre, los arreboles de aquella tarde, las púrpuras de aquel ocaso, las armonías compuestas por la mezcla del susurro de las arboledas con el rumor de las brisas, los aromas embriagadores, las perspectivas inacabables, embellecíanse, como á porfía, para despedirse y separarse de aquellos sus reyes y señores, los cuales habían completado las grandezas del Universo con las inspiraciones del arte.» (CASTELAR, E., El suspiro del moro..., ob. cit., p. 453-454).
} 
Castelar y, sobre todo por Fernández y González, cobra vida para el lector del XIX e invita a la contemplación literaria de su relevancia todavía en el XXI actual.

\section{Bibliografía}

a) PRIMARIA

Alarcón, P. A. de, El suspiro del moro, Granada, Ventura y Sabatel, 1867.

CASTELAR, E., El suspiro del moro: Leyendas, tradiciones, historias referentes a la conquista de Granada, Madrid: Imprenta de Fortanet, 1885.

Chateaubriand, F. R., Vicomte de, «Le Dernier Abencerage» en Atala. René. Le Dernier Abencerage, Paris, Pourrat Frères, 1834 [1826].

Conde, J. A., Historia y dominación de los árabes en España, París, Baudry, 1820.

Fernández y GonZÁLEZ, M., Allah-Akbar, Granada, M. Sanz, 1849.

, El laurel de los siete siglos, Madrid, Gaspar y Roig, 1850.

, La Alhambra: leyendas árabes, Madrid, Martínez, 1856.

, «La toma de Granada y el suspiro del moro», en El Museo Universal, 1 de enero de 1860, pp. 2-3 y El Museo Universal, 8 de enero de 1860, pp. 10-11.

Guevara, A. de, Libro primero de las epístolas familiares, Valladolid, Real Academia Española, 1950-1952 [1539-1541], pp. 253-254

IRving, W., Chronicle of conquest of Granada, Philadelphia, Carey, Lea \& Carey, 1829.

, Crónica de la conquista de Granada, Jorge W. Montgomery (trad.), Madrid, I.

Sancha, 1831.

Cuentos de la Alhambra, D.L.L. (trad.), París, Librería Hispano-Americana, 1833.

Mármol Carvajal, L. del, Historia del rebelión y castigo de los moriscos del Reyno de Granada, Madrid, M. Rivadeneyra, 1852 [1600].

b) SECUNDARIA

Carrasco Urgoiti, M. S., El moro de Granada en la literatura: del siglo XV al XIX, Tesis (Versión digital), Alicante, Biblioteca Virtual Miguel de Cervantes, 2010 [1956]. Disponible en: http://www.cervantesvirtual.com/obra/el-moro-degranada-en-la-literatura-del-siglo-xv-al-xix /

Correa Rodríguez, P., «Estudio preliminar», en Ginés Pérez de Hita, Historia de los bandos de Zegríes y abencerrajes (primera parte de las Guerras Civiles de Granada), Granada, Universidad de Granada, 1999, pp. IX-CLXXXI.

FERNÁNDEz PRIETO, C., «Literatura y nacionalismo español (1808-1900)», en José María Pozuelo Yvancos (dir.), Historia de la literatura española 8: Las ideas literarias 1214-2010, Madrid, Crítica, 2011, pp. 439-544.

Ferreras, J. I., La novela en España. Historia, estudios y ensayos. Tomo III: Siglo XIX. Primera parte (1800-1868), Madrid, La biblioteca del laberinto, S.L., 2010. 
María Teresa del Préstamo Landín

GonzÁlez FerRín, E., Historia general de Al Ándalus: Europa entre Oriente y Occidente, Córdoba, Almuzara, 2006.

Ladero Quesada, M. Á., Castilla y la conquista del reino de Granada, Granada, Diputación provincial de Granada, 1987.

«Isabel y los musulmanes de Castilla y Granada», en Julio Valdeón Baruque (ed.), Isabel la Católica y la Política: ponencias presentadas al I Simposio sobre el reinado de Isabel la Católica, celebrado en las ciudades de Valladolid y México en el otoño de 2000, Valladolid, Ámbito D.L., 2001, pp. 91-114. 